\title{
A Low Temperature Structure of Nonane-1,9-Diaminium Chloride Chloroacetate: Hydroxyacetic Acid (1:1)
}

\author{
Agnieszka Paul • Maciej Kubicki
}

Received: 24 February 2010/Accepted: 31 December 2010/Published online: 14 January 2011

(C) The Author(s) 2011. This article is published with open access at Springerlink.com

\begin{abstract}
The crystal structure of nonane-1,9-diaminium chloride chloroacetate-hydroxyacetic acid (1:1) was determined by X-ray diffraction at $100(1) \mathrm{K}$. The asymmetric unit is composed of diaminium dication, chloroacetate and chloride anions, and neutral hydroxyacetic acid molecule. The aliphatic chain of 1,9-diamine is fully extended and it deviates only slightly from the perfect all-trans conformation. The two acidic residues are also nearly planar. The layer structure is obtained as a consequence of hydrogen bond interactions of a different lengths, with $\mathrm{N}-\mathrm{H}$ and $\mathrm{O}-\mathrm{H}$ groups playing the role of donors and oxygen atoms and chloride cations as acceptors. The pattern of $\mathrm{H}$ bonding is investigated by graph-set analysis. Crystal data: crystal system: monoclinic, $a=4.6418$ (2) $\AA, b=25.5128$ (11) $c=15.9943$ (9) $\AA, \beta=99.784(5)^{\circ}, Z=4$, space group: $\mathrm{P} 21 / \mathrm{c}, V=1866.6(1) \AA^{3}$.
\end{abstract}

Keywords Nonane-1 - 9-diaminium - Conformation . Crystal packing $\cdot$ Hydrogen bonds - Layer structure

\section{Introduction}

Aliphatic $\alpha, \omega$-diaminoalkanes are the biogenic diamines widely spread in nature, that are essential in many biological processes, e.g. in stabilization of the conformation of nucleic acids [1]. These compounds mostly occur in the form of dications, as a consequence of the strong basic properties of the two amino groups attached at both ends of the aliphatic chain. This predictable tendency to accept

\footnotetext{
A. Paul $(\bowtie) \cdot$ M. Kubicki

Faculty of Chemistry, Adam Mickiewicz University,

Grunwaldzka 6, 60-780 Poznań, Poland

e-mail: agapaul@amu.edu.pl
}

protons and to form salts with both, organic and inorganic acids, together with a significant flexibility of the chain fragment and tendency towards creation of the highly symmetric networks, can be used in so-called crystal engineering [2], i.e. in designing new materials with expected features. Such a predictable motifs in the crystal structures, giving rise to a layer structure, were already investigated in the series of hexane-1,6-diamine and butane-1,4-diamine salts [3, 4].

Only five structures deposited in the Cambridge Structural Database [5] (no multiple determinations, herein and after) contain the nonane-1,9-diaminium fragment [6-10], and in one of these cases the dication itself is disordered [9], while in the other some atoms are not localized [6]. In all these structures, either organic or organometallic, the diaminium cation is involved in the construction of the layer structure and interacts with the other components of the structures through N-H...A hydrogen bonds of different length and likely of different strength, what is a typical feature of diamine salts in general ([3] and references herein). The diamine fragment can play the role of a communication tool between polymerizing species in order to transmit the information about the structure ordering from one location to another [6], of a coupling agent within metallic dimers [7], or even it can undergo the reversible and quantitative intercalation in a layer structure [8].

Beside these nonane-1,9-diaminium salts, the CSD contains also another similar long-chain diaminium structures, namely 1,7-heptanediamine dihydrochloride [11], 1,12-diaminododecane dihydrochloride monohydrate [12] and 1,10-diaminodecane tetrachlorozincate [13]. In the two first cases the diaminium fragments are fully extended, while in the last structure the terminal part of the diaminium is bent, despite the similar type of interactions, due to size of the counterion. It is difficult to assess the influence 
of even-odd number of carbon atoms in the aliphatic chain on diaminium cation conformation because the number of 'even' structures in CSD is significantly larger than the 'odd' ones, what probably reflects the trend in easiness of crystallization process. Moreover, there is a shortage of the salts with analogous anions for the proper statistics.

On the acetic side, there are 17 structures in CSD containing hydroxyacetate anion (7 organic, 10 organometallic), and 5 structures that have neutral hydroxyacetic acid fragment (3 organic, 2 organometallic). When these data are compared with 17 structures containing chloroacetate anion (10 organic, 7 organometallic) and 12 structures containing chloroacetic acid (10 organic, 2 organometallic), the contents of neutral and deprotonated forms are in accordance with their pKa values, equal 2.87 and 3.83 for, chloroacetic and hydroxyacetic acids, respectively. To our best knowledge there are no data about the structures containing both these acids and their anions simultaneously. In the present case, however, the general tendency is preserved, as only chloroacetate fragments are found deprotonated.

In the course of our studies on the aliphatic $\alpha, \omega$-diaminoalkane salts we obtained the monocrystals of nonane1,9-diaminium chloride chloroacetate-hydroxyacetic acid (1:1) (hereinafter referred to as $\mathbf{1}$ ). The structure is composed of the diaminium dication, the two different monoanions and additionally one neutral molecule, which still participates in hydrogen interactions.

\section{Experimental}

In order to synthesize the compound 1, $1 \mathrm{mmol}(0.158 \mathrm{~g})$ of nonane-1,9-diamine was dissolved in $3 \mathrm{ml}$ of methanol : water : nitromethane solution (1:1:1) with $2.4 \mathrm{mmol}$ $(0.227 \mathrm{~g})$ of chloroacetic acid (excess of acid was added to assure the complete protonation of both amino groups). The milk-like mixture was then heated and afterwards placed in a well-ventilated room for a slow crystallization. After the evaporation of the solvents without obtaining appropriate crystals (oleaginous solution), the mixture was recrystallized in $3 \mathrm{ml}$ of 2-propanol. After few days the transparent crystals suitable for X-ray diffraction were obtained. Scheme 1 presents the synthesis path.
The partial transformation of the chloroacetic acid into hydroxyacetic acid may be explained by the short heating time. The reaction path strongly resembles the one used in the industrial production of hydroxyacetic acid, where sodium hydroxide is used instead of basic diamine molecule [14]. The melting point was measured using MELTEMP capillary device (Electrothermal, USA), with temperature raising rate of $2 \mathrm{~K} / \mathrm{min}$.

\section{Single Crystal X-ray Analysis}

The diffraction data were collected at 100(1) K with CrysAlis CCD [15] on XCALIBUR EOS four circle diffractometer, with graphite-monochromatized $\mathrm{MoK}_{\alpha}$ radiation ( $\lambda=0.70073 \AA$ ). The temperature was controlled by Oxford Instruments Cryosystems cooling device. The data were corrected for Lorentz-polarization and absorption effects. The unit cell parameters were determined by a least squares fit of 15619 reflections chosen from the whole experimental set. The structure was solved with SIR92 [16] and refined with the full-matrix least-squares procedure on $F^{2}$ by SHELXL97 [17], using scattering factors incorporated in SHELXL97, molecular graphics were prepared using XP [18], Mercury [19] and CrystalExplorer [20].

The function $\Sigma w\left(\left|F_{\mathrm{o}}\right|^{2}-\left|F_{\mathrm{c}}\right|^{2}\right)^{2}$ was minimized, with $w^{-1}=\left[\sigma^{2}\left(F_{\mathrm{o}}\right)^{2}+0.0383 \cdot P^{2}\right]\left(P=\left[\operatorname{Max}\left(F_{\mathrm{o}}^{2}, 0\right)+2 F_{\mathrm{c}}^{2}\right] / 3\right)$. All non-hydrogen atoms were refined anisotropically. The hydrogen atoms were localized from the difference Fourier maps and freely refined. The relevant crystallographic parameters, data collection and refinement details are listed in Table 1.

\section{Results and Discussion}

\section{Molecular Geometry}

The content of the asymmetric part of the unit cell of $\mathbf{1}$ in a thermal ellipsoid representation together with the labeling mode is shown in Fig. 1. Some relevant geometrical parameters are listed in Table 2.

The carbon chain of diaminium fragment presents alltrans conformation, with a slight curvature towards organic
Scheme 1 The synthesis path of the title compound
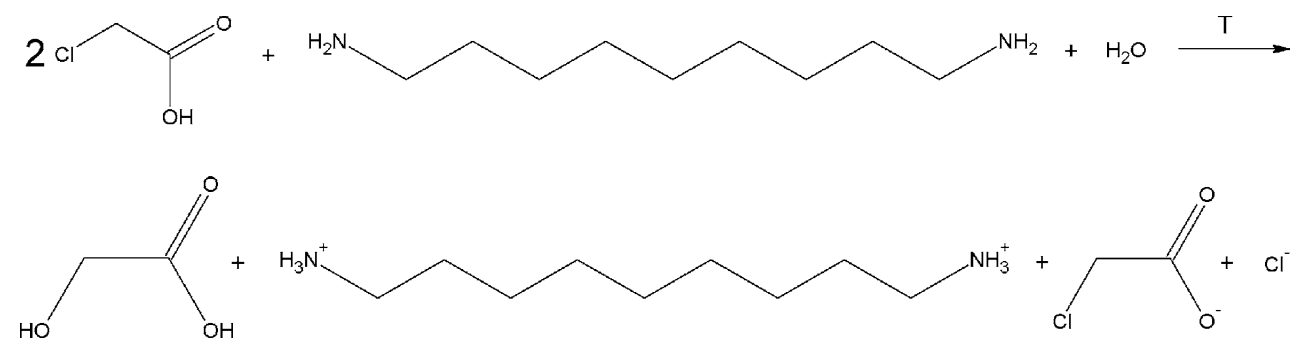
Table 1 Crystal data, data collection and structure refinement

\begin{tabular}{|c|c|}
\hline CCDC deposit number & 760720 \\
\hline Formula & $\begin{array}{l}\mathrm{C}_{9} \mathrm{H}_{24} \mathrm{~N}_{2}^{2+} \cdot \mathrm{Cl}^{2-} . \\
\mathrm{C}_{2} \mathrm{H}_{2} \mathrm{ClO}_{2}^{-} \cdot \mathrm{C}_{2} \mathrm{H}_{4} \mathrm{O}_{3}\end{array}$ \\
\hline m. p. $(\mathrm{K})$ & $357 *$ \\
\hline Formula weight & 365.29 \\
\hline Temperature $(\mathrm{K})$ & $100(1)$ \\
\hline Wavelength & 0.7173 \\
\hline Crystal system & Monoclinic \\
\hline Space group & $\mathrm{P} 2{ }_{1} / \mathrm{c}$ \\
\hline$a(\AA)$ & $4.6418(11)$ \\
\hline$b(\AA)$ & $25.5128(11)$ \\
\hline$c(\AA)$ & $15.9943(9)$ \\
\hline$\beta\left(^{\circ}\right)$ & $99.784(5)$ \\
\hline$V(\AA 3)$ & $1866.58(15)$ \\
\hline$Z$ & 4 \\
\hline$d_{x}(g \mathrm{~cm}-3)$ & 1.300 \\
\hline Absorption correction & multi-scan \\
\hline$T_{\min } / T_{\max }$ & $0.9740 / 1.0000$ \\
\hline$F(000)$ & 784 \\
\hline$\mu(\mathrm{mm}-1)$ & 0.37 \\
\hline Crystal size (mm) & $0.4 \times 0.2 \times 0.005$ \\
\hline$\Theta$ range $\left(^{\circ}\right)$ & $3.0-29.0$ \\
\hline \multirow[t]{3}{*}{$h k l$ range } & $h=-6 \rightarrow 6$ \\
\hline & $k=-34 \rightarrow 33$ \\
\hline & $i=-21 \rightarrow 21$ \\
\hline Reflections collected/unique & $57619 / 4763$ \\
\hline$R_{\mathrm{int}}$ & 0.058 \\
\hline Completeness & $95.6 \%$ \\
\hline Refinement method & Full-matrix least-squares on $F^{2}$ \\
\hline Data/parameters/restrains & $4763 / 319 / 0$ \\
\hline Goodness of fit on $F^{2}$ & 0.89 \\
\hline Final $R$ indices $[I>2 \sigma(I)]$ & $R_{1}=3.3 \%, w R_{2}=6.4 \%$ \\
\hline Final $R$ indices (for all data) & $R_{1}=6.4 \%, w R_{2}=6.9 \%$ \\
\hline $\begin{array}{l}\text { Largest diff. peak and hole } \\
\left(\mathrm{e} / \AA^{3}\right)\end{array}$ & 0.36 and $-0.27 \mathrm{e} / \AA^{-3}$ \\
\hline
\end{tabular}

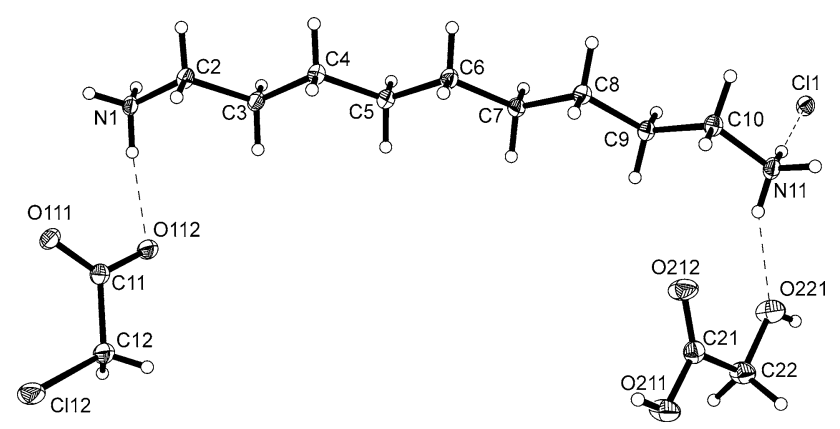

Fig. 1 A view of the chemical unit of 1 [18]. Displacement ellipsoids are drawn at the $50 \%$ probability level, $\mathrm{H}$ atoms are depicted as spheres of arbitrary radii. Hydrogen bonds are drawn as dashed lines
Table 2 Selected geometrical parameters $\left(\AA{ }^{\circ}\right)$ in $\mathbf{1}$, with the s.u.'s in parentheses

\begin{tabular}{llll}
\hline N1-C2-C3-C4 & $-179.6(1)$ & C7-C8-C9-C10 & $-172.56(1)$ \\
C2-C3-C4-C5 & $177.8(1)$ & C8-C9-C10-N11 & $173.3(1)$ \\
C3-C4-C5-C6 & $-173.8(1)$ & O112-C11-C12-C112 & $-0.7(2)$ \\
C4-C5-C6-C7 & $175.8(1)$ & O111-C11-C12-C112 & $179.9(1)$ \\
C5-C6-C7-C8 & $-173.0(1)$ & O212-C21-C222-O221 & $0.2(2)$ \\
C6-C7-C8-C9 & $173.1(1)$ & O211-C21-C222-O221 & $-179.0(1)$ \\
N1-C2 & $1.489(2)$ & C10-N11 & $1.484(2)$ \\
C2-C3 & $1.512(2)$ & C11-O112 & $1.247(2)$ \\
C3-C4 & $1.521(2)$ & C11-O111 & $1.265(2)$ \\
C4-C5 & $1.522(2)$ & C11-C12 & $1.513(2)$ \\
C5-C6 & $1.518(2)$ & C12-C112 & $1.784(2)$ \\
C6-C7 & $1.520(2)$ & C21-O212 & $1.204(2)$ \\
C7-C8 & $1.520(2)$ & C21-O211 & $1.315(2)$ \\
C8-C9 & $1.521(2)$ & C21-C222 & $1.503(2)$ \\
C9-C10 & $1.511(2)$ & C222-O221 & $1.413(2)$ \\
\hline
\end{tabular}

acids, which are involved in the hydrogen bonds. The deviation from perfectly extended conformation of dication is $22.6(1)^{\circ}$ (the intersection angle between two planes created by three terminal carbon-carbon-nitrogen atoms). The $\mathrm{C}-\mathrm{C}$ bond lengths in aliphatic chain depicts the repeating pattern at both sides-the bonds lengths between two carbon atoms $(\mathrm{C} 2-\mathrm{C} 3$ and $\mathrm{C} 9-\mathrm{C} 10)$ located in the vicinity of nitrogen atoms are significantly shorter (in the term of 3 s.u.'s) than in the remaining part of the chain. Both organic acid forms-neutral and deprotonatedpresent almost planar conformations (cf. Table 2), with chlorine atom situated nearly in the plane of oxygen and carbon atoms (chloroacetate anion) and with all oxygen atoms situated in the plane common with carbon atoms (hydroxyacetic acid).

The $\mathrm{C}-\mathrm{O}$ distances in chloroacetate residue are slightly different, what is probably the result of different number of hydrogen bonds accepted by given oxygen atom: the shorter $\mathrm{C}-\mathrm{O}$ distance is observed for the oxygen atom that is involved in only one short hydrogen bond, while the longer-for that which accepts two such bonds (cf. Table 3).

\section{Hydrogen Bond Patterns}

The hydrogen bonds, together with electrostatic cationanion interactions, are the main packing force in the investigated structure. To describe the repeating pattern of H-bonds we use graph-set notation [21, 22]. The noncentrosymmetric dication, with its two diaminium groups, is the donor of total of seven hydrogen bonds (one hydrogen atom participates in the bifurcated hydrogen bond; it might be noted that unlike in the previously analyzed structures both these bonds are of comparable length 
Table 3 Hydrogen bond geometry

\begin{tabular}{lllll}
\hline $\mathrm{D}-\mathrm{H} \cdots \mathrm{A}$ & $\mathrm{D}-\mathrm{H}$ & $\mathrm{H} \cdots \mathrm{A}$ & $\mathrm{D} \cdots \mathrm{A}$ & $\mathrm{D}-\mathrm{H} \cdots \mathrm{A}$ \\
\hline $\mathrm{N} 1-\mathrm{H} 1 \mathrm{~A} \cdots \mathrm{Cl} 1^{\mathrm{i}}$ & $0.885(16)$ & $2.426(17)$ & $3.2258(14)$ & $150.6(13)$ \\
$\mathrm{N} 1-\mathrm{H} 1 \mathrm{~B} \cdots \mathrm{O} 111$ & $0.915(18)$ & $1.935(18)$ & $2.8361(16)$ & $167.8(15)$ \\
$\mathrm{N} 1-\mathrm{H} 1 \mathrm{C} \cdots \mathrm{Cl} 1^{\mathrm{ii}}$ & $0.858(18)$ & $2.340(18)$ & $3.1591(13)$ & $159.9(14)$ \\
$\mathrm{N} 11-\mathrm{H} 11 \mathrm{~A} \cdots \mathrm{C} 11$ & $0.937(18)$ & $2.179(18)$ & $3.1122(14)$ & $174.2(14)$ \\
$\mathrm{N} 11-\mathrm{H} 11 \mathrm{~B} \cdots \mathrm{O} 112^{\mathrm{iii}}$ & $0.895(18)$ & $2.006(19)$ & $2.8310(16)$ & $152.6(15)$ \\
$\mathrm{N} 11-\mathrm{H} 11 \mathrm{C} \cdots \mathrm{O} 221$ & $0.860(16)$ & $2.097(17)$ & $2.8892(18)$ & $153.0(14)$ \\
$\mathrm{N} 11-\mathrm{H} 11 \mathrm{C} \cdots \mathrm{O} 212$ & $0.860(16)$ & $2.331(16)$ & $2.9748(17)$ & $131.8(13)$ \\
$\mathrm{O} 211-\mathrm{H} 211 \cdots \mathrm{O} 111^{\mathrm{iv}}$ & $0.803(18)$ & $1.803(19)$ & $2.5816(15)$ & $162.9(18)$ \\
$\mathrm{O} 221-\mathrm{H} 223 \cdots \mathrm{O} 112^{\mathrm{v}}$ & $0.760(19)$ & $2.051(19)$ & $2.7511(15)$ & $153.4(19)$
\end{tabular}

Symmetry codes (i) $-\mathrm{x},-\mathrm{y},-\mathrm{z}+1$; (ii) $\mathrm{x}, \mathrm{y}, \mathrm{z}-1$; (iii) $\mathrm{x}+1, \mathrm{y}, \mathrm{z}+1$; (iv) $\mathrm{x}+1,-\mathrm{y}+1 / 2, \mathrm{z}+1 / 2$; (v) $\mathrm{x}, \mathrm{y}, \mathrm{z}+1$

and likely of comparable strength), and the additional two bonds are created by hydroxyl groups of the neutral hydroxyacetic acid molecule (cf Table 3 ).

On one side of the aliphatic chain two hydrogen atoms are involved in creation of the ring $R_{4}^{2}(8)$ with two chloride anions-the motif that is typical for simple diamine salts ([3], and references therein), while the last available $\mathrm{N}-\mathrm{H}$ bond is directed towards chloroacetic anion. On the other end of the chain, there is only one $\mathrm{N}-\mathrm{H}$ bond directed towards the chloride anion, another one points to the chloroacetic acid residue, while the last $\mathrm{N}-\mathrm{H}$ group makes the bifurcated hydrogen bond, which involves oxygen atoms of the neutral molecule of hydroxyacetic acid, to form a small ring $R_{1}^{2}(5)$. Taking into account the whole dication connected via $\mathrm{H}$-bond network with chlorine anions, we find the chain $\mathrm{C}_{2}^{1}(14)$ and the larger rings $R_{4}^{2}(28)$, while the combination of the dication and the chloroacetate anion results in another, longer chain $C_{2}^{2}(16)$. Finally, the chains composed only of organic acids residues (neutral and charged) are also present and depicted with $\mathrm{C}_{2}^{2}$ (9) descriptor (cf Fig. 2).

The three dimensional structure is therefore acquired through the mutual arrangement of the motifs described above, rings and chains, repeated in the $a c$ plane. This hydrogen bond network governs the molecular packing and as a consequence the layer structure is obtained, with distinguished and alternating levels of dication-chloride rings and organic acid chains (cf Fig. 3).

The main chain of the dication remains unfolded because the counter ions create the regular layer without the thickness fluctuation. Nevertheless one cannot deny the existence of the potentially stabilizing $\mathrm{H} \cdots \mathrm{H}$ contacts, that occur between the two parallel aliphatic chains, even if they are longer than the sum of van der Waals radii. The analysis of the Hirshfeld surfaces [23] and "fingerprints" of the intermolecular distances for hydrogen-hydrogen contacts show, that almost $71 \%$ of close contacts is that of hydrogen-hydrogen (cf Fig. 4). The importance of such interactions is more pronounced in the structures with purely long aliphatic chains, where the all-trans conformation dominates, hence in $\mathbf{1}$ this is more likely a secondary effect.

\section{Conclusion}

The crystal structure of nonane-1,9-diaminium chloride chloroacetate-hydroxyacetic acid (1:1) has been determined by X-ray diffraction at $100(1) \mathrm{K}$. The compound crystallizes in the monoclinic $\mathrm{P} 2{ }_{1} / \mathrm{c}$ space group, with all ions and neutral molecules in nearly planar conformations. The dominating packing forces organizing the layer structure are the hydrogen bonds, existing between cations
Fig. 2 Graph set analysis of (1), [18] presenting the main rings and chains motifs, symmetry codes (i) $\mathrm{x}, \mathrm{y}, \mathrm{z}$; (ii) $-\mathrm{x},-\mathrm{y}, 1-\mathrm{z}$; (iii) $-\mathrm{x},-\mathrm{y}$, $-\mathrm{z}$; (iv) $\mathrm{x}, \mathrm{y},-1+\mathrm{z}$; (v) $-1+\mathrm{x}$ $1 / 2-\mathrm{y},-1 / 2+\mathrm{z}$; (vi) $-1+\mathrm{x}$, $1 / 2-\mathrm{y}, 1 / 2+\mathrm{z}$; (vii) $-1-\mathrm{x}$, $-1 / 2+\mathrm{y}, 1 / 2-\mathrm{z}$; (viii) $-1-\mathrm{x}$, $-1 / 2+y, 3 / 2-z$; (ix) $-1-x$, $-1 / 2+\mathrm{y},-1 / 2-\mathrm{z} ;(\mathrm{x})-1+\mathrm{x}$, $1 / 2-\mathrm{y},-3 / 2+\mathrm{z}$

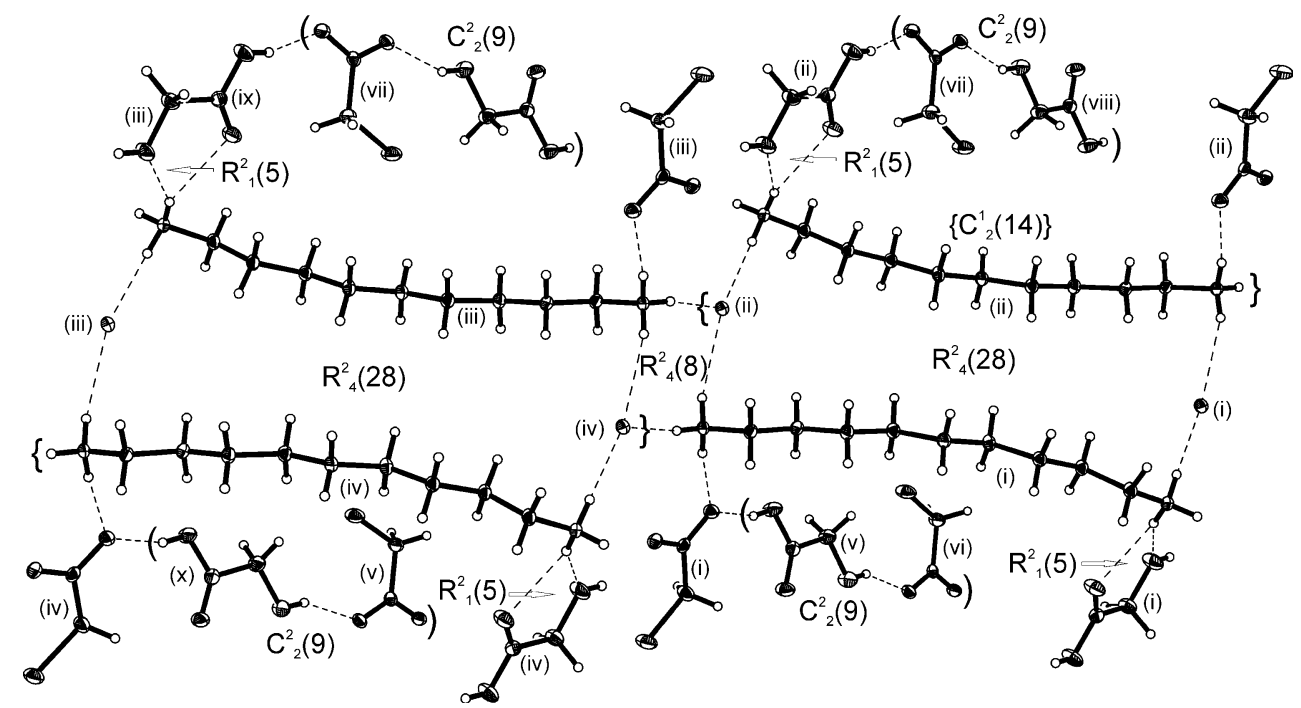




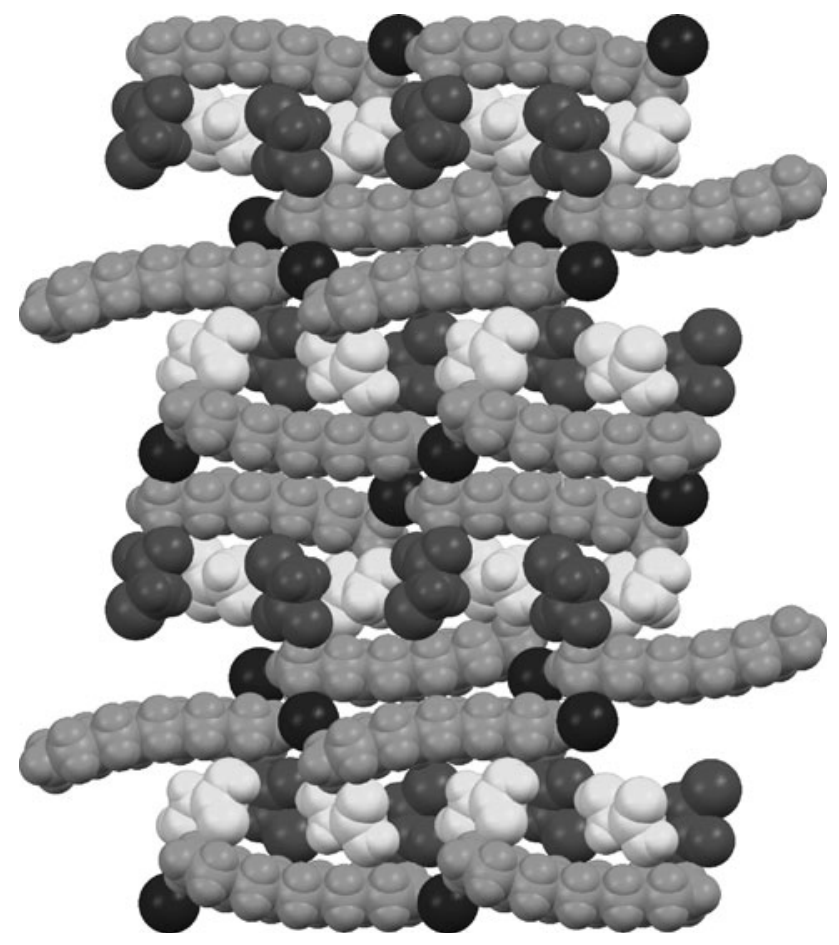

Fig. 3 Layer structure of the title structure [19], view along a direction, layers parallel to $a c$ plane

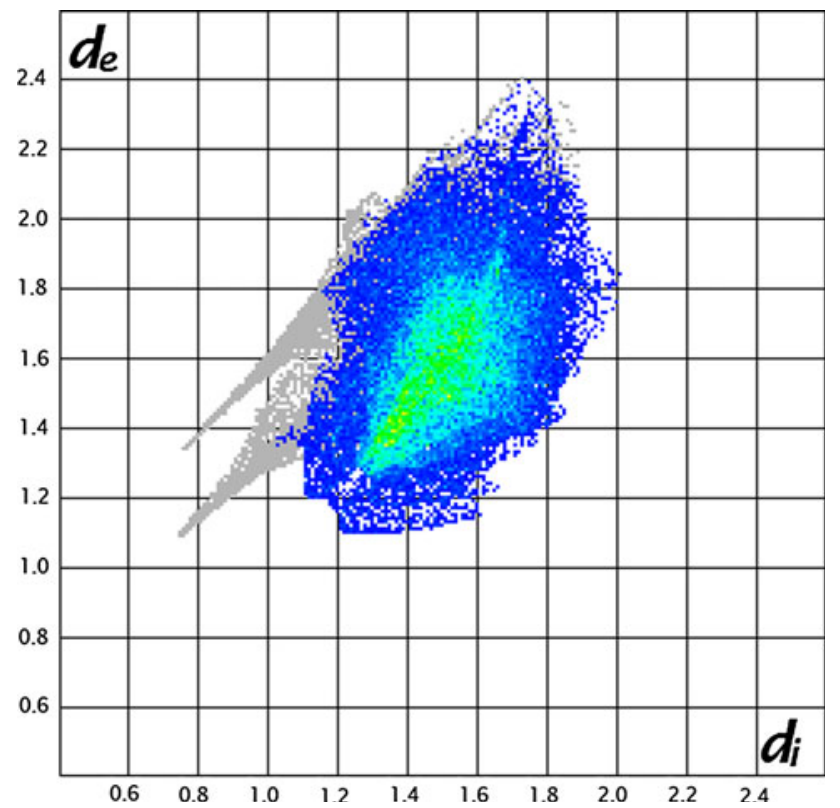

Fig. 4 The 2D "fingerprint" plot presenting the hydrogen-hydrogen contacts [20]

and anions as well as between anions and neutral molecules. The secondary stabilizing hydrogen-hydrogen interactions may be partially responsible for the all-trans conformation of the aliphatic chain.

\section{Supplementary Material}

Crystallographic data (excluding structure factors) for the structure reported in this article have been deposited with the Cambridge Crystallographic Data Centre and allocated the deposition number CCDC 760720. Copies of the data can be obtained free of charge on application to CCDC 12 Union Road, Cambridge CB21 EZ, UK (Fax: (+44) 1223 336-033; e-mail: data_request@ccdc.cam.ac.uk).

Open Access This article is distributed under the terms of the Creative Commons Attribution Noncommercial License which permits any noncommercial use, distribution, and reproduction in any medium, provided the original author(s) and source are credited.

\section{References}

1. Jaskólski M (1987) Acta Cryst C43:1761-1763

2. Pospieszna-Markiewicz I, Radecka-Paryzek W, Kubicki M (2006) Acta Cryst C62:0399-o401

3. Paul A, Kubicki M (2009) J Mol Struct 938:238-244

4. Paul A, Kubicki M (2010) J Mol Struct 966:107-112

5. Allen FH (2002) Acta Cryst B58:380-388

6. Feng P, Bu X, Stucky GD (2000) Inorg Chem 39:2-3

7. Affronte M, Casson I, Evangelisti M, Candini A, Carretta S, Muryn CA, Teat SJ, Timco GA, Wernsdorfer W, Winpenny REP (2005) Angew Chem Int Ed 44:6496-6499

8. Reiss GJ, Engel JS (2004) Z Naturforsch 59b:1114-1117

9. Visi MZ, Knobler CB, Owen JJ, Khan MI, Schubert DM (2006) Cryst Growth Des 6:538-545

10. Grandin A, Borel MM, Raveau B (1985) J Solid State Chem 60:366-375

11. Brisson J, Beauchamp AL (1988) Acta Cryst C44:1152-1153

12. McNeil R, Scheidt WR, Thomas JK (1981) Mol Cryst Liq Crys 78:85-114

13. Ning G, Yong-Hua L, Guang-Fu Z, Shi-Quan X (1992) Acta Cryst C48:650-652

14. Ebmayer et al. (1998) Process for preparing a particularly pure glycolic acid, US Patent No 5.723.662, 3 March 1998

15. Oxford Diffraction (2009). CrysAlis PRO. (Version 1.171.33. 36d). Oxford Diffraction Ltd, Yarnton, England

16. Altomare A, Cascarano G, Giacovazzo C, Gualardi A (1993) J Appl Cryst 26:343

17. Sheldrick GM (2008) Acta Cryst A64:112-122

18. Siemens (1989) Stereochemical Workstation Operation manual. Release 3.4. Siemens Analytical X-ray Instruments Inc., Madison, Wisconsin, USA

19. Macrae CF, Bruno IJ, Chisholm JA, Edgington PR, McCabe P, Pidcock E, Rodriguez-Monge L, Taylor R, van de Streek J, Wood PA (2008) J Appl Cryst 41:466-470

20. Wolff SK, Grimwood DJ, McKinnon JJ, Turner MJ, Jayatilaka D, Spackman MA (2010) CrystalExplorer (Version 2.2), University of Western Australia, Australia

21. Etter MC, MacDonald JC, Bernstein J (1990) Acta Cryst B46:256-262

22. Bernstein J, Davis RE, Shimoni L, Chang N-L (1995) Angew Chem Int Ed Engl 34:1555-1565

23. Spackman MA, Jayatilaka D (2009) Cryst Eng Comm 11:19-32 